\title{
UNA CLASE DE ÉTICA MÉDICA DEL PRESIDENTE ALLENDE
}

\author{
A class of bioethics by Dr. Allende
}

Imagino que en junio de 1972, el presidente Allende debe haber estado lleno de preocupaciones. La situación del país no era nada fácil por esos días. Sin embargo, se tomó el tiempo para aceptar una invitación que le hizo mi padre, el Dr. Armando Roa, a dictar una clase de Ética Médica a los alumnos de Medicina de la Universidad de Chile. Imagino también, que esa invitación se cursó a través de Laura Allende, su hermana, que conocía a mi padre. La experiencia, a la que asistí siendo muy niña en la Clínica Psiquiátrica Universitaria, fue inolvidable.

No se trataba de interrumpir sus labores para acudir a una clase magistral, a un debate en el Congreso, o a un organismo internacional. Se trataba de algo muy sencillo, que no le daría brillo alguno, pero que debe haber considerado importante, pues Salvador Allende era médico y la salud pública había sido su pasión.

Era ese un Chile en el que dos personas de tiendas políticas muy distintas podían confluir y valorar el sentarse a pensar en intereses comunes, con el respeto que surge de la consideración del otro desde su valía personal.

$\mathrm{Al}$ abordar el problema de la ética en relación a la salud pública, Salvador Allende le da una dimensión social, distinta a la que usualmente se le atribuye y que se centra más bien en las decisiones individuales.

Resulta, pues, tan extraordinariamente interesante como necesario volver a leer esta clase y recuperar la reflexión que el país nos exige en torno a las dimensiones éticas de la salud desde una perspectiva de bien colectivo.

Natalia Roa

El presidente de la República, doctor Salvador Allende, ha dictado en 1972 la clase sobre "Ética y Comunidad" en el curso de Ética Médica de la Escuela de Medicina de la Universidad de Chile. Con amena agilidad y riqueza conceptual, el Presidente le ha dado vida a problemas demasiado trivializados a través de monótonas repeticiones de argumentos no siempre aceptables para el buen sentido.

La asignatura de Ética Médica abarca temas como el de la conducta ante los contraceptivos, el aborto, el sexo, los trasplantes de órganos, la hipnosis, las enfermedades invalidantes, la muerte, las drogas, la investigación científica, la superstición, etc. En medio de ese variado conjunto, las cuestiones 
relacionadas con ética y política, y ética y comunidad, son sin duda el trasfondo esclarecedor de todas, y de ahí la importancia de que un político clave, como lo es el presidente Allende, entregara sus propias perspectivas. Lo ha hecho a plena satisfacción de los numerosísimos alumnos, médicos y paramédicos que tuvieron el gozo de escucharlo.

Agradecemos en nombre de los estudiantes del curso y en el nuestro propio el entusiasmo y generosidad mostrada por el Presidente al aceptar la invitación y desear cumplirla con presteza. Ello muestra por sí solo amor a la educación y a la salud de los semejantes. Destacamos al respecto, que es la primera vez en la historia de la Facultad de Medicina que un presidente de la República habla, no en un acto solemne, sino que en una clase "anónima cualquiera" de una asignatura de una Escuela universitaria. Como el hecho revela de suyo a un espíritu capaz de discernir lo importante en lo aparentemente insignificante, parece valioso sellarlo para el recuerdo. A tal fin invitamos especialmente a la clase a nuestro amigo Hernán Romero. Nadie como él, con su agudo poder de observación y su mirada abierta a todo evento digno, podía dejar escrita con perdurabilidad la atmósfera misma de aquella tarde memorable.

Armando Roa

Profesor de Ética Médica de la Facultad de Medicina de la Universidad de Chile.

\section{PALABRAS DEL PRESIDENTE DE LA REPÚBLICA, DOCTOR SALVADOR ALLENDE GOSSENS, A LOS ALUMNOS DE PRIMER AÑO DE LA CÁTEDRA DE ÉTICA, DE LA FACULTAD DE MEDICINA DE LA UNIVERSIDAD DE CHILE.}

Santiago, junio 30 de 1972.

Futuros colegas, colegas y amigos, profesor Armando Roa, decano de la Facultad de Medicina, director de la Escuela de Medicina:

He saludado al entrar al profesor Hernán Romero a quien me unen muchos años de una mantenida y a veces discutida amistad. Vengo a conversar con ustedes. Y me acompañan el ministro de Salud Pública y el comandante José Mela, Edecán de Servicio.

Primero quisiera manifestarles que en esta actividad que me busqué durante 18 años (porque ustedes saben que he sido candidato cuatro veces hasta llegar a la Presidencia), uno tiene obligaciones diversas y difíciles de cumplir; por ejemplo, en la mañana de hoy, debí ir a conversar con la Academia de Altos Man- dos dependiente del Ministerio de Defensa, y desarrollar algunas ideas frente a los jefes de las Fuerzas Armadas, Almirantes, Generales, Jefes de Oficiales, y además altos personeros de la administración civil, para exponerles algunas ideas sobre el desarrollo económico de las Fuerzas Armadas y la participación de ellas, tanto en la seguridad como en la defensa nacional. Declaro que esta tarea denominada erradamente también, "clase magistral", era difícil para mí, pero mucho y mucho más difícil es conversar con ustedes que son alumnos de un curso de Ética Médica y que dicta el profesor Armando Roa.

(...)

Y lo digo honestamente, y se lo decía al llegar, si de mí hubiera dependido habría preferido conversar con ustedes acerca de algunos aspectos de la Medicina Social. Porque la he vivido, he participado en la gestación de ese tipo de medicina en nuestro país, y sé la interrelación que existe entre la posibilidad de otorgar esta medicina y la realidad económica de un país. Pero, lamentablemente, las cosas no son como uno quiere y trataré de dialogar 
con ustedes diciéndoles sí, que yo debería ser alumno de este curso y aprovechar la vasta preparación del profesor Roa, con quien en la vida he tenido contactos esporádicos, pero a quien conozco porque una hija mía fue su alumna y en sus apuntes muchas veces leí algunos matices sobre sus clases de Psiquiatría, que me recordaban la época en que fui estudiante, en que trabajé en la Casa de Orates, donde viví seis años, lo que hace que algunos digan que no debería haber salido de ahí (risas). Pero la verdad estricta es que eso me dio un conocimiento mucho más amplio de la gente, y es cierto aquello que dice: “Aquí no están todos los que son, ni son todos los que están”. Por esa razón quizás pude alcanzar en el camino de la vida algunas responsabilidades que ejerzo, sin olvidarme, fundamentalmente, que estas responsabilidades las he adquirido porque soy médico. Con ello quiero señalar que los que estudiaron Medicina y los que hemos ejercido parcialmente, como en el caso mío, quiero decir durante algunos años Medicina, tenemos indiscutiblemente una formación, un vínculo con la persona humana que nos hace ser más permeables a la vida misma de la persona humana.

\section{(...)}

Yo me recuerdo, entonces, y cómo no hacerlo frente a ustedes -fíjense- yo ingresé al primer año de Medicina, el año 1926. Yo podría darles a ustedes el nombre de los que fueron mis maestros, para quienes tengo y tendré siempre un recuerdo agradecido, pero no quiero hacerlo porque quizás involuntariamente pudiera olvidarme del nombre de alguno de ellos. Pero podría decir tan solo, que fui alumno de Benavente, profesor de Anatomía, hombre sencillo, modesto, de pequeña estatura, con una gran formación cultural, que trabajaba las Preparaciones en las cuales hacía su clase como un artista. Fui alumno de un hombre físicamente distinto, pero intelectualmente similar, extrovertido, con un gran vozarrón, que se tomaba los bigotes, y haciendo sus clases prácticamente nos enseñaba a través de una lección que tenía profundo y hondo contenido de experiencia técnica y de contenido humano: Lucas Sierra.
Y fui alumno y conocí a hombres que hicieron clases de lo que llamaban en esa época Medicina Interna.

Fui alumno de Noé, el profesor Noé que con su fino sentido irónico le decía a los muchachos que salían mal en los exámenes, y expresaban su desesperanza: ¡Eh, váyase a Leyes, carrera fácil y lucrativa! ¡Eh, no se quede en la Medicina! (risas).

En esa época eran tan distintas las cosas, tan diferentes, sobre todo para un estudiante que llegaba de provincia, como yo, de una provincia cercana, Valparaíso, pero Santiago es Santiago, y la bullente vida universitaria era y es muy distinta a la realidad de los estudiantes en los liceos provincianos.

La Avenida La Paz era un solo y enorme barrial; los estudiantes de provincia vivíamos en lo que se llamaban los "pilchenes" universitarios. Y esos “pilchenes”, que eran pensiones, tenían un valor, en esa época, ¡imagínense ustedes!, yo pagaba 120 pesos al mes viviendo en el "Belisario Torres", que queda aquí en la Avenida La Paz.

De ahí nos echaron por una huelga, porque el postre de dulce de membrillo que nos daban era transparente (risas), absolutamente transparente. Entonces, vagué por distintas pensiones y había que entrar a ellas a veces fingiendo que era alumno de un curso superior; porque tenían su experiencia estas dueñas de pensiones, ya que a veces, y no con poca frecuencia, se mudaban o nos mudábamos los estudiantes a fin de mes sobre todo cuando se había acumulado la deuda de dos o tres meses (risas).

Era una época tan distinta y tan diferente, eran cursos que podríamos llamar multitudinarios. En el primer año de Medicina, éramos 600 alumnos y eso significaba que los ayudantes tenían que atender 40 o 50 alumnos; no había contacto, diálogo directo entre ayudante y alumno, mucho, mucho menos entre profesor y alumno. Eran los tiempos increíblemente absurdos, y era así, en que en un solo día, en un largo mesón, en la vieja Escuela que se quemó, estaban las Comisiones, por ejemplo, en el primer año de Medicina en que dábamos Física, Química, Biología y Botánica. Y había que rendir los exámenes uno 
tras otro, y resulta que llegaba un compañero a dar su cuarto examen habiendo aprobado en los otros tres, salía mal en el cuarto y debía repetir todos los exámenes en marzo.

Yo les contaba un día que vine a conversar con los alumnos, (por una magnífica iniciativa de la Facultad de Medicina, hoy pueden serlo también los trabajadores) para diferenciar esta realidad de hoy con la de ayer, les decía que en ese primer año en un momento determinado dando examen de Botánica, 26 o 30 alumnos fueron reprobados por una sola pregunta; por suerte, uno de esos compañeros hizo un "torpedo”, este llegó a mis manos y cuando me senté frente al profesor, me preguntó: “¿Qué es Geotropismo?” Yo le dije: "movimiento autanógeno paratónico", me puso un cinco y todavía no sé lo que es eso (risas).

Eso es una etapa de mi vida, que en realidad, nunca olvidaré, como tampoco olvidaré la primera clase a que asistí, de un hombre extraordinario, a quien llamaban los profesores y los alumnos "El Gabacho Croizet", hacía clases de Anatomía Patológica, seguramente todos los colegas que están aquí, que son profesores son alumnos de Croizet.

Yo estaba -recuerdo- en el anfiteatro en la penúltima fila, el cadáver cubierto con una sábana y entra el profesor, robusto, de anchas espaldas, con unas gafas de tipo antiguo, voz ronca, directo, cáustico, pero en el fondo humano, y le pregunta al jefe de Clínica Quirúrgica, “¿De qué murió este enfermo?” Peritonitis “ ¿Causas?” Se le extirpó la vesícula: “¿Qué dificultades tuvieron?” Bueno, un hombre un poco grueso, dificultades, la anestesia fue incompleta, trabajamos bastante, pero no hubo accidente. “ ¿No hubo accidente?” “¿No se saltó el cístico?”. No. “Cómo se iba saltar el cístico cuando no llegaron al cístico, llegaron al colédoco":

Calculen ustedes el impacto para un alumno que llega a una clase como esa y que en la primera lección se encuentra con una realidad que lo hace meditar. Lo hace meditar en la técnica y en la ciencia que es la Medicina. Lo hace pensar en que gente que ha estudiado, se ha sacrificado, que no solo ha aprendido sino que está enseñando, en un momento de- terminado puede cometer o comete errores, que pudieran aparentemente no tener justificación y que la tienen, porque todos estamos limitados, a pesar de que aparentemente se tenga un gran dominio de la ciencia.

Y esa misma mañana, como quien dice, para completar, en un vuelco de escepticismo, el segundo caso fue todavía más dramático, porque también asistió el jefe de la otra Clínica y ahí estaba el cadáver y la misma pregunta: ¿De qué murió el enfermo? Peritonitis. “¿Qué tuvo?” Un absceso apendicular. “¿Hubo dificultades?" No. "Vea usted, compresas”. Y saca del abdomen del cadáver una compresa. Se había quedado dentro, en la operación.

Uno piensa, entonces, en la responsabilidad profesional; piensa, inclusive, y no sé cómo expresarlo, ¿cómo expresarlo? ¿Cómo se sentirá desde el punto de vista de la responsabilidad, de la ética profesional, el cirujano que actuó, los ayudantes que participaron, el conjunto de personas que intervinieron?

Y si comienzo esta conversación de esta manera es para señalar cuán limitada es la posibilidad del hombre médico frente a tantas circunstancias, hasta llevarlo al error en el caso individual que he narrado y que se manifiesta en niveles superiores, en las condiciones de vida y de existencia de la gente. Con ello estoy diciendo, en el segundo caso, que nosotros los médicos tenemos la cortapisa de una realidad que se expresa en la sociedad que hace que el hombre tenga o no más resistencia a las enfermedades que inciden en el proceso inicial de su propia gestación, que se manifiesta a lo largo de las horas primeras. $\mathrm{Y}$ no en vano, para caracterizar la reacción del hombre, alguien y con mucho peso, nos enseñó que "el niño es el padre del hombre", con lo cual se está señalando que en las etapas primeras, iniciales de la existencia, se empieza a marcar el carácter, el temperamento, la reacción, la emotividad, lo que es esencia, o puede llegar a ser, la personalidad humana.

(...)

$\mathrm{Y}$ esto tiene como base, entre otras cosas, y esencialmente, las condiciones del medio ambiente, la realidad económico-social.

Cuando hemos dicho muchas veces, con dolor de chileno, con amargura de patriota, 
con honda amargura de padre, que en este país, en donde la Medicina ha alcanzado niveles superiores o los alcanzados en otros países, en donde inclusive las instituciones, como expresión de nuestra estructura social, tienen una validez y una actitud y una vigencia que no poseen otros países, en este país donde hay múltiples leyes sociales, entre otras algunas en las cuales participamos, que dan derecho a la atención médica por ejemplo, a la familia del imponente obrero, que establece la asignación familiar, la ventaja prenatal, que indica la obligación de la madre grávida a ir al control médico para recibir el estipendio que le permitirá alimentarse mejor, y como consecuencia de ello, que su hijo tenga mejores condiciones. En este país, repito, donde la legislación establece el descanso, la asignación tanto en la etapa puerperal como en la de lactancia, en este país, hay 600 mil niños con una menor valía intelectual por no haber recibido en los primeros ochos meses de su vida las proteínas necesarias para el desarrollo normal de su inteligencia.

Todos estos hechos tienen que ir formando en el joven y en el médico la conciencia de sus grandes posibilidades, pero al mismo tiempo la conciencia de sus grandes limitaciones. Las grandes posibilidades deben estimularle para una acción proyectada mucho más allá de las fronteras importantísimas del caso individual y proyectarlo en el ámbito social, y comprender la importancia trascendente que significa ser médico de una sociedad que demanda, que reclama salud. Pero, darse cuenta -como decía hace un instante que este reclamo de la salud y la posibilidad de entregar la defensa de ella en el equilibrio biológico está en relación con los fenómenos ambientales, la alimentación el trabajo, la vivienda.

Pienso, entonces que ustedes, alumnos de esta clase del brillante profesor Roa, comprenderán que para conversar con ustedes, y en relación directa con el tema que el profesor me ha planteado hice una pauta y extraje unas cuantas líneas y, a mis años, uno puede sentarse y lo perdonan.

Por ejemplo, ¿cuál es la dimensión fundamental de una ética médica? Para un especialista norteamericano, autor del libro
Las Profesiones de Medicina, el concepto de la ética de la profesión médica tiene el contenido de una profesión propiamente tal y esto connota el conocimiento específico de un oficio, de una ocupación. Es decir, en un conjunto de conocimientos -estoy leyendo lo escrito por él- habilidades y destrezas adquiridas a través de la educación médica y dirigidas a un campo específico de aplicación, el fomento de la salud y la prevención, curación, rehabilitación de la enfermedad.

Por otro lado, el concepto de profesión en su acepción semántica, es el de profesar una fe, una mística, el tener una vocación, en este caso: la medicina.

Entonces hay -como ustedes ven- dos concepciones: una que explica la profesión en sí misma y lo que ello encierra, y la otra la de vocación, la de mística, de fe, que son factores que deben conjugarse y que indiscutiblemente en la formación del profesional médico entregado a su Escuela de Medicina que es técnica debe de haber un equilibrio entre estos aspectos que encierra la definición que acabo de leer.

Yo pienso que durante muchos años, en las Escuelas o en la Escuela de Medicina nuestra primó fundamentalmente la formación profesional más que estimular, impulsar, destacar y convertir en mística la vocación del estudiante.

Por eso, no es extraño, yo acabo de aprender -allí, en la oficina del profesor Roa-que este curso comienza en el año 1968 cuando emerge la Reforma Universitaria. ¿Y antes, por qué no? ¿Acaso no era una disciplina que pudiera caer? No era una necesidad que se sintiera, no era una proyección de la técnica y el ejercicio de ella frente al enfermo, que permitiera al hombre una cultura, [al] que llegó a ser profesor universitario, poder especular, poder divagar, razonar o sentir la necesidad de esta enseñanza?

Por eso, repito, para mí es importante señalar que nace esta Cátedra de la cual ustedes participan, porque tanto el profesor Roa como Alfredo Jadresic, han señalado que este curso del cual ustedes forman parte, prácticamente de la clase en sí misma, que participan, que ustedes se sienten incorporados a lo que 
el maestro está planteando y con la vivacidad con que el profesor Roa me decía: "parta como quiera y va a llegar donde no quiere" pero donde lo van a llevar la inquietud o las interrogantes de estos alumnos que constituyen un curso muy calificado, capaz de un análisis de lo que se les está diciendo.

Por eso es útil señalar, entonces, que este curso de Ética Médica emerge de la expresión de la Reforma Universitaria y la Reforma Universitaria en sí, ¿qué refleja? ¿Qué señala? ¿Qué representa? Romper las viejas concepciones, las deterioradas estructuras de una universidad enclaustrada en el profesionalismo, en el perfeccionamiento estilizado del conocimiento técnico en las distintas ramas del saber humanístico, pero una universidad quieta frente a los problemas de la gente, una universidad silenciosa y ausente de las grandes batallas del pueblo, una universidad no comprometida con los procesos de transformación social, que en el caso fundamental de la Medicina conlleva la necesidad imperiosa de entenderlo, porque de allí nace fundamentalmente la limitación de nuestro arte y de nuestra ciencia como lo he señalado.

Por ello, entonces, y ustedes más que otros al ser alumnos de esta clase, tienen que entender la proyección trascendente de una Reforma Universitaria, que a alumnos del primer año, los hace incorporarse a una Cátedra que nosotros nunca tuvimos, ya que en esta más que centenaria Escuela de Medicina, solo a partir del año 1968 se dicta esta clase de Ética Médica y se empieza a hablar a los jóvenes, oyendo a su vez lo que ellos dicen, que es: cómo y por qué existe una cátedra de esta naturaleza.

Es por eso, también, que es conveniente y quizás útil señalar que en la formación del médico, como lo dije hace un instante, la especialización propiamente tal nace de la enseñanza que se entrega a la Escuela de Medicina y por cierto, que esta enseñanza se ha ido mutando. Cambiando, variando a través del proceso que más tarde, si tengo tiempo, analizaré, de la demanda cuando el hombre toma conciencia de sus derechos de una atención médica que para él no es sino la consagración de un derecho.
Y deben pensar ustedes que a pesar que parezco joven, no lo soy tanto, (risas) no soy de la época del "parche poroso" ni de la "nitrozona”, pero soy de la época de la Beneficencia, del sentido de la caridad, cuando existía el indigente, cuando por el esfuerzo privado -muchas veces- se mantenían los hospitales, cuando en los hospitales estaban de administradores no los médicos, sino precisamente filántropos, cuando el personal que trabajaba en los hospitales vivía dentro de ellos y podía salir, a veces, dos o tres horas al mes. Y yo, por ejemplo, que era interno de la Casa de Orates -estoy hablando del año 1926-1928- entré a la Escuela en el año 1926 bueno, veía con angustia, por ejemplo, que gente que trabajaba ahí solo podía salir dos horas al mes y la demás gente salía acompañada de una viejita que nunca la dejaba, por lo tanto era imposible conversar con ninguna de las personas que trabajaban fuera de la Casa de Orates. Ustedes se ríen, en el fondo de este comentario no hay una insinuación vulgar, es un hecho. ¿Cuál era la dependencia de ese personal, hasta dónde era una vida enclaustrada, cómo no existían las ocho horas, cómo existía un trabajo ilimitado, cómo no había horas extraordinarias, cómo no había una dimensión de diferencias exageradas entre el médico y la enfermera, época en que no había enfermeras universitarias, época en que el personal auxiliar, no tenía presencia, época en que no se comprendía que la Medicina es además, y tendrá que ser siempre, un trabajo de conjunto y un trabajo de equipo, donde el médico tenía todas las prerrogativas, menos aquellas que le impedían administrar el hospital y lo hacían depender de un hombre que no era médico.

Pero vino la transformación de la Beneficencia, del Servicio Médico, del Seguro Social, de la Protección de la Infancia y de la Sanidad, en un servicio único, en el Servicio Nacional de Salud, embrión de lo que debe ser, a mi juicio, el Servicio Único de Salud.

Pues bien, la sociedad le da al médico derechos y prerrogativas que siempre tuvo y que dicen relación, por ejemplo, con la autonomía en el ejercicio de su profesión, con la autorregulación de sus ingresos, parcialmente 
limitados hoy día, cuando desde hace algunos años, y me cupo en ello responsabilidad, el médico pasó a ser funcionario de un Servicio Nacional de Salud quedando siempre un margen -y no poco amplio- para el ejercicio liberal de la profesión. En seguida el médico en sí mismo es prácticamente en esencia el que controla su propio rendimiento, y el médico puede y tiene -a través de su organización que es el Colegio Médico- posibilidad de participar en la dictación de las leyes relacionadas con la salud. Además, la sociedad le entrega a la universidad los medios económicos para ir formando a los futuros médicos. $\mathrm{Y}$ aquí tengo una cifra que quiero darles a ustedes: el año 1970 se gastaron -por ejemplo- alrededor de US\$6.448.600 (dólares) para la formación de 2.159 alumnos. Es decir, se gastó un promedio de US\$2.986 (dólares) por alumno en un año. Según la estadística, este costo en América Latina es el más alto, excepto las Indias Occidentales, vale decir Jamaica y Barbados. Quiero también señalar que de acuerdo con las estadísticas -y declaro que si hay un error es de responsabilidad del Ministro de Salud Pública a quien lo consulté- en el año 1970, a pesar del alto gasto, de la alta inversión, no hubo un incremento del hombre-médico ni siquiera en un 0,1\% y fueron Chile y Paraguay los que mantuvieron estático el crecimiento del hombre-médico a pesar de la demanda de salud que reclaman los pueblos.

Y a pesar -y la estadística lo dice y no he tenido tiempo de discutirlo con el doctor Carlos Concha- que hubo, según me dijeron, para el mismo período un porcentaje de postulantes a la Escuela de Medicina que creció en Chile en un $20 \%$.

Esto indica que el presupuesto nuestro, país pobre, en preparar los médicos, en enseñar Medicina, en adiestrar técnicamente a los jóvenes que van a ejercerla, es extraordinariamente elevado frente a nuestra realidad. Ustedes son caros, jóvenes, bastante caros. Y eso implica responsabilidad, y forma parte de la ética con que ustedes deben responder.

Responsabilidad, porque es todo el pueblo el que a través de los impuestos financia lo que más necesita, que es el cuidado de su salud. Y, por lo tanto, tener conciencia de este hecho, ver el privilegio que significa ser estudiante de una universidad reformada y ser estudiante de Medicina, que implica romper las exigencias que se hacen para ingresar a otras disciplinas en el sentido de tener mejores condiciones expresadas en la Prueba Académica, o en las pruebas finales. Tener conciencia del esfuerzo social que implica el que podamos preparar los médicos, y lamentablemente constatar, que a pesar de este esfuerzo tenemos déficit extraordinarios que limitan también en forma extraordinaria los planes de desarrollo de una medicina que necesitamos dar.

Hace poco, y tengo entendido que es iniciativa del Ministro, quien les va a entregar unas cuantas páginas para que se las lleven a sus casas, las lean, las discutan después, donde están trazadas las grandes líneas que promueve este Gobierno en la protección y defensa de la salud.

Conversando con el colega y con el doctor Infante, director del Servicio Nacional de Salud, analizando los planes hacia el futuro, llegábamos a la conclusión de que Chile tiene 6 mil médicos, pero para los planes mínimos que se han proyectado, se necesitan 9 mil médicos.

¿Y cuántas matronas? ¿Y cuántas enfermeras? ¿Y cuánto y cuánto más personal de las carreras que inciden y complementan la carrera médica? Problema también que lleva en sí mismo algo que ustedes deben comprender es de extraordinaria importancia. Más allá, mucho más allá del esfuerzo material que hace el país para que ustedes sean médicos está la demanda urgente, apremiante, de miles de chilenos que nunca han podido comprar la salud en el sentido de pagar la consulta a la que en función de las leyes tienen derechos limitados por las disponibilidades humanas; $y$ frente a eso se plantea un problema de ética: ¿Puede el médico egresado de la universidad negarse a ir a cumplir con su profesión, en función de la vocación que debe tener y del sentido superior que implica ser médico, a los sectores rurales en donde todavía la Medicina en parte no llega? ¿Y es aceptable y concebible, y no rompe todos los preceptos básicos de un sentido ético y moral, que el muchacho 
formado con el esfuerzo material de un pueblo, con el sacrificio de sus maestros y profesores, con la atención comprensiva de los ayudantes graduados, busque las expectativas materiales que se le presentan más allá de las fronteras del país y en función de estas expectativas abandone su Patria que le dio el título con el esfuerzo de un pueblo, a sabiendas que ese pueblo reclama, necesita urgentemente atención médica? ¿No es romper valores que tienen un sentido profundo y que deben estar incrustados en la conciencia de cada uno de ustedes al saber y comprender el alcance y contenido del esfuerzo nacional que se hace por una parte? Pero mucho más todavía, a sentir y comprender la angustia que significa saber que miles y miles de nuestros compatriotas deberían tener derecho a una atención médica que no se la podemos dar porque carecemos de recursos humanos.

Esto ha significado un desafío para el médico chileno, que ha debido entender la relación entre la medicina del individuo y la medicina social.

La medicina social pretende poner al alcance de todos los chilenos la medicina individual, en forma integral. La medicina social alcanza su fin cuando logra dar a cada ser humano la atención singular que este requiere. La medicina, a nuestro juicio, debe ser una síntesis entre lo técnico y lo humano. La medicina es un diálogo entre los técnicos y las personas, su familia y su organización. Solo en ese diálogo se une lo técnico y lo humano. $\mathrm{Y}$ es por eso necesario destacar que por esta Universidad, y aún antes que existiera esta tan necesaria Cátedra, hubo maestros que comprendieron y enseñaron esto que es el contenido característico y fundamental de la Medicina, el vínculo y el nexo entre lo técnico y humano.

El médico chileno ha pasado desde el médico de familia en... ¡brum! al médico de una medicina social, hasta el médico integrante de los equipos especializados, de una labor de conjunto, y esto como consecuencia de una sociedad que entiende lo que es la medicina y que la reclama.

Las estructuras de Salud, han ido modificándose y el cuerpo médico, y esto hay que destacarlo, algunos de los que estamos aquí, fundamentalmente a Hernán Romero y a mí, por ser los más viejos, nos ha correspondido una participación más directa en estos procesos de la estructura de los servicios médicos, como consecuencia -repito- de las demandas y ello se ha expresado a través del Servicio Nacional de Salud y después en el SERMENA, siendo primeramente, una atención limitada en los sectores de empleados.

Quiero hacer una referencia breve a lo que ha ocurrido en la transformación de los Servicios de Salud Pública de nuestro país en los últimos años, destacando que en esencia han sido -y es curioso- los médicos mismos los que fueron permeabilizándose para ir limitando la medicina individual y abrir camino a la medicina funcionarizada.

Y aquí, entonces, incide también un aspecto aparentemente difícil de diseñar de la ética: ¿Resistieron o no resistieron los médicos, como cuerpo, como en otros países, el avance de la concepción de una medicina funcionarizada? No. ¿Hubo discrepancias? Sí. Pero fue un médico, un senador conservador, Exequiel González Cortés, el que creó el seguro de enfermedad, la vieja Ley llamada 4054, y la Ley de Accidentes del Trabajo, la Ley 4055. Y fue otro médico conservador, senador de la República y maestro cuyas clases eran notables, Eduardo Cruz-Coke, quién abrió algunos aspectos directamente destinados a acentuar la protección al binomio madre-niño. Y cosa curiosa, en el extremo aparente o real, me ha correspondido a mí, socialista, ser también un factor que señala que no hay fronteras ideológicas cuando hay una concepción de responsabilidad, posibilitar la creación del Servicio Nacional de Salud, ampliar la atención médica de la familia del imponente obrero, modificar las prestaciones económicas, crear el estatuto del médico funcionario y la propia ley del Colegio Médico.

De la misma manera que modificar la ley de enfermedades profesionales, de accidentes del trabajo convirtiendo las enfermedades profesionales como un accidente, y haciendo que ellos tuvieran un contenido social. Cabría preguntarse entonces desde el punto de vista de la ética o la responsabilidad profesional, ¿es 
que los colegas, que antes que nosotros ejercieron su profesión, vulneraban principios éticos porque no aplicaban sus conocimientos y se limitaban, por ejemplo, en el caso de la vieja Ley 4054 antes que se extendiera la atención de la familia a la atención médica de la familia del imponente obrero? ¿Se limitaban tan solo a atender al imponente? ¿Es que alguien podría decir que en un foco infectocontagioso, no iba a irradiar el imponente enfermo hacia los suyos su propia enfermedad? ¿Puede preguntarse si acaso aquellos médicos que combatieron la dictación de las leyes que comento, lo hacían en función de defender un derecho a la autorregulación de sus ingresos, que la sociedad siempre y aún ahora les reconoce? ¿ $\mathrm{O}$ es que acaso en ellos no tuvo profunda significación la enseñanza recibida en una Escuela de Medicina destinada esencialmente a preparar profesionales, técnicamente eficientes, pero al margen de los problemas de la comunidad; satisfechos de entregar en el caso individual el aporte de su ciencia y de su arte, pero limitados por la propia enseñanza de una concepción liberal de la Medicina, de comprender que centímetros más allá del caso examinado estaba otro niño o una mujer, hijo o compañera del enfermo que atendía, que reclamaba sus servicios y no lo otorgaba sino por una actitud generosa, si es que lo hacía -porque estaba al margen de la ley el derecho de la mujer, esposa del imponente-, a tener atención médica excepto durante el parto. Y los hijos del imponente hasta los dos años y nada más.

Entonces, ustedes ven jóvenes alumnos que en la formación de ustedes incide y se proyecta la obligación responsable que van a contraer, y si hoy varios maestros les hablan un lenguaje distinto que el de ayer nos hablaban a nosotros, ustedes van acumulando firmemente y sintiendo intensa y hondamente una responsabilidad que nosotros intuíamos y que logramos descubrir ya como adultos, después, frente a lo que es la necesidad de atención médica y que es la obligación entregarla.

Nos costó a nosotros darnos cuenta que es cierto el axioma que dice: "A mayor pobreza, mayor enfermedad y a mayor enfermedad, mayor pobreza”. Y eso es una gran realidad en estos países. Y por eso es que nosotros también concebimos al médico como un factor en el proceso organizativo de la sociedad, como un factor dinámico, bullente, capaz de trasmitir el porqué el médico deber ser y entender, y hay que ir -dentro de la realidad de cada país; de hecho llamados en vía de desarrollo- a realizar los cambios estructurales que permitan en esencia elevar los niveles de vida de los pueblos.

¿Qué son nuestros países mirados desde el punto de vista socio-económico? Son los llamados países dependientes, países productores de materias primas, países potencialmente ricos, que viven una vida de miseria.

¿Qué es el subdesarrollo en esencia? Enfermedad, incultura, miseria moral y miseria biológica.

¿Cómo se relaja el hombre de nuestro pueblo ante la frustración de su propia vida y de su propia existencia?

¿Cómo pesa en el desarrollo económico, en el nivel intelectual, y en el nivel moral, el escapismo que escandaliza en la juventud y que es inadmisible llegar a justificarlo o a entenderlo? Pero, que lo vive nuestro pueblo en la dimensión brutal de una enfermedad social como el alcoholismo, en un país en que hay 300 mil alcohólicos crónicos y un millón de bebedores habituales excesivos. Piensen ustedes. Hoy -no sé si el titular, no tuve tiempo, corresponde a la realidad- leí que en la Unión Soviética se decía que un impacto en el desarrollo económico era el excesivo alcoholismo que apunta entre los soviéticos. Piensen ustedes, en un país que ha alcanzado su nivel; piensen en un país como el nuestro y piensen ustedes la responsabilidad tremenda del médico frente al alcohólico. Piensen ustedes cómo hay que abrir camino a la concepción de que es un enfermo y que ese enfermo tiene como raíz una desigualdad social que él no creó, que a él le impusieron. ¿̇Y cómo hay que hacer entender que el tratamiento médico propiamente tal es en el caso nuestro limitadísimo? ¿Y cómo la concepción hoy día, abarca no sólo mirar el proceso de la enfermedad del alcohólico sino como un aspecto de algo mucho más trascendente, y 
que lo habrá planteado en densidad profunda y permanente el profesor Roa en su Cátedra, que es la salud mental.

Entonces, se plantea, para todos nosotros, y también para ustedes, problemas de ética que van más allá de la ética personal, que podríamos llamar aventuradamente, y quizás por un error, y lo cometo voluntariamente, lo que podríamos llamar una ética social en el sentido profesional técnico y humano.

Entonces, yo pienso y repito que son los médicos los que pueden y deben ser, por su propia formación, por su vinculación con el proceso del hombre enfermo, porque están en la raíz de la enfermedad que en la inmensa mayoría de los casos tiene el acento de una injusticia expresada en el bajo salario, en la falta de vivienda, en la alimentación insuficiente.

Cómo no preguntarse hasta dónde y hasta cuándo las dos terceras partes de la humanidad van a sufrir miseria, van a sufrir material y espiritualmente.

¿Cómo es posible que en este continente latinoamericano, como lo he dicho tantas y tantas veces, haya 140 millones de habitantes analfabetos y semianalfabetos, que falten 19 millones de viviendas, que haya 11 millones o trece de parados absolutos y más de 60 millones de personas que tienen trabajos ocasionales?

¿Cómo el médico no va a preguntarse, cómo en un país como el nuestro, donde la democracia tiene una auténtica dimensión, cómo en un país como el nuestro en que las instituciones tienen una solidez que hace que Chile sea uno de los tres países del mundo en que el Congreso tiene 160 años de vigencia ininterrumpida. En este país donde hay partidos políticos y organizaciones sindicales y colegios profesionales, en este país donde los grandes déficit siguen y siguen acumulándose frente a las estructuras económicas que determinan una forma de vida social?

Como ministro de Salubridad Pública de Pedro Aguirre Cerda en 1940, hice la primera Exposición de la Vivienda en Chile, frente al Club de la Unión, en esa época el Club de la Unión era el centro de la oligarquía, hoy es un restaurante malo y barato. En esa época hice la primera Exposición de la Vivienda y los técnicos hicieron repetir que en Chile faltaban, hace 32 años, 320 mil viviendas. Hoy día faltan 500 mil viviendas, porque nunca ningún gobierno, a pesar de todos los empeños, y no niego lo que otros gobiernos, antes que nosotros, han hecho, nunca un gobierno y tampoco nosotros hemos construido en relación con el aumento vegetativo de la población. Entonces, es una bola de nieve que se va incrementando. $\mathrm{Na}$ cen y nacen más niños y no se construyen los metros cuadrados para ellos. Y eso se proyecta en la alimentación cuando la producción agropecuaria está por debajo, también, del crecimiento vegetativo.

Se ha logrado en la educación pública obtener las cifras ideales frente a las posibilidades de matrícula en la Educación Básica, se ha aumentado extraordinariamente en la Enseñanza Media y hoy día hablamos de las universidades de Chile, donde hoy -y es importante señalarlo- para nuestra población, en este momento, más de 100 mil estudiantes universitarios.

Entonces, también, cabe preguntarse, ¿no forma parte de la propia concepción de la ética el hecho de que el médico pueda ser indiferente a estos aspectos que a veces en las cátedras nos enseñan, pero que son una realidad?

¿Podría avanzar la Medicina, en un país donde no se construyen las casas necesarias para el aumento vegetativo de la población, donde un porcentaje altísimo de nuestros compatriotas están subalimentados?

¿Puede el médico conformarse con el dominio exclusivo de su técnica y su ciencia y no preocuparse de esos factores que influyen directa y extraordinariamente, en la eficacia de su tratamiento y el rendimiento de su ciencia y de su arte?

$¿$ Puede ser indiferente $-\mathrm{y}$ se los planteo a ustedes, jóvenes, que van a ser médicos en algunos años más- por ejemplo, que en el comercio de la terapéutica, vale decir los productos terapéuticos, no haya un control? ¿Por qué no se preguntan: por qué fue necesario que se dictara el Formulario Nacional de Salud y por qué indiscutiblemente habrá que terminar con la gama de especialidades y de 
nombres de fantasía de productos que tienen en esencia la misma droga, pero que se disfraza con una propaganda brutal que encarece el producto y que hace que en realidad, inclusive, se deforme la propia conciencia profesional al extremo de que los médicos, muchas veces lisa y llanamente, se acostumbran a un producto y si ese producto por equis razones no existe, no buscan la alternativa de otro producto? Importante (aparentemente no mucho), decisivo, extraordinario, sobre todo, para un país como el nuestro que solo tiene en ese aspecto una industria de transformación, vale decir, que somos dependientes.

Hoy, a la hora de almuerzo, conversaba con el doctor Horwitz, gran médico chileno, que hace años fue director de la Organización Sanitaria Panamericana, hombre de vasto prestigio y discutíamos y conversábamos el problema de la penicilina semisintética, la ampicilina. Nos planteábamos el problema: $¿$ Conviene a Chile ampliar las viejas instalaciones que tiene el Instituto Bacteriológico, frente -inclusive- a la opinión técnica de algunos médicos que sostienen que para algún tipo de gérmenes, es necesario esa penicilina o conviene más, manteniendo la producción pequeña en que está, frente a la demanda necesaria, importar el ácido que es lo básico y patentado y en seguida así preparar la sal? Vamos a ser dependientes, claro, pero somos dependientes en muchos otros aspectos, porque no es fácil llegar a la síntesis en países como el nuestro, en donde se requiere una investigación científica y un alto nivel técnico. Estos son problemas que se plantean y que es importante dilucidar. Como también, y lógicamente inciden -y quiero plantearlo antes que se me escape en esta improvisación-, fíjense ustedes, por ejemplo, cuando se crea un derecho a través de una ley de previsión social, para tener atención médica -y eso implica, en el caso de enfermedad, el subsidio-, ¿es o no indiferente que el médico entienda que al otorgar los subsidios debe proceder desde el punto de vista ético, con la certeza de que el hombre que lo consulta está enfermo, y que merece por lo tanto el descanso, y que al otorgarle el descanso le está otorgando un ingreso que necesita el hombre, en reemplazo del salario que recibe? Pero que en este mismo instante y en las distintas latitudes, desde Arica a Magallanes, de la precordillera al mar, donde hay consultorios, hay otros médicos que están ejerciendo ese mismo derecho que les da la ley, pero que en esencia representa un egreso de millones y millones de escudos que pesan sobre el proceso del Seguro Social.

Y si acaso eso es importante destacarlo lo es también y mucho más preguntarse, por ejemplo, si acaso en Chile y en este momento la libre elección limitada, con las restricciones que tiene el Servicio Nacional de Empleados, debe continuar o debe darse paso a un Servicio Único de Salud, y hacer de la medicina, la medicina de equipo que es fundamental, y no distinguir la medicina para el obrero y campesino y otra para el empleado público o para el empleado particular. Y yo me pregunto, si desde el punto de vista de la ética ¿es aceptable o criticable -pregunto, y ustedes se responderán- por ejemplo, en el caso del Servicio que comento, cuando la prestación médica se da dentro de establecimientos que se han levantado con el esfuerzo de todos, que el médico puede allí obtener ingreso adicional y el personal que con él trabaja no lo recibe?

¿Por qué? ¿Por qué puede ese personal tener la obligación de atender al que llega, ejerciendo un derecho, con un bono que va a entregarle al médico? Y el médico va a pedir un ingreso, $y$, ¡caramba que es importante la ética profesional para que el médico mismo autorregule sus ingresos. Y si acaso no se le ha enseñado que hay valores distintos al valor material, si acaso no ha entendido que el dinero no regula ni debe regular la vida de un hombre, si acaso no entiende que más allá del beneficio personal está su responsabilidad, puede haber y los hay, algunos médicos que acumulan atenciones de enfermos que no puede significar la prestación médica eficiente y eficaz porque la atención de una consulta entraña, por lo menos, en un caso corriente, 20 minutos a media hora, en el diálogo que tiene que haber entre el enfermo y el médico. El problema no es diagnosticar mirando y hay que entender que frente a un hombre que es médico, está-genéricamente hablando-un 
hombre que es enfermo, pero que tiene también el sentido del respeto y la dignidad, que el médico debe respetar fundamentalmente en la entrega de su ciencia y de su técnica.

Son problemas que inciden en la cátedra del profesor Roa que van más allá de los hechos que habitualmente se plantean, pero que los van a golpear a ustedes tarde o temprano; espero que más temprano que tarde y que ojalá ni siquiera los golpeen, porque es obligación nuestra buscarles la solución antes que se profundicen más y que creen más problemas serios.

Por eso, quiero también insistir, para tratar de encontrar la pauta que no había tocado, que la ética médica, como tarea a desarrollar se puede expresar en que ella debe resumirse en dignidad y respeto.

¿Cómo poner en la medicina social el respeto y la dignidad? Descubrí la respuesta en nuestra tarea como médico. La medicina, como dijera hace un instante, no solo es tratar, es respetar la dignidad, no solo ofrecer tratamiento. Es el proceso social el que va dando al hombre conciencia de sus derechos, y eso también tiene que entenderlo el médico y si he hablado del médico como pionero y organizador de una comunidad distinta, así también el médico debe entender que el hombre, como consecuencia de las injusticias, las desigualdades, como expresión de que no hay fronteras, cuando las comunicaciones alcanzan las dimensiones mundiales que tienen, va tomando conciencia que en otras partes, en otras latitudes, lo que para él es una esperanza es un derecho, lo que para él es una quimera es una realidad. $Y$ entonces va reclamando esos derechos.

$\mathrm{Y}$ en el caso concreto nuestro, por ejemplo, cuando llega un gobierno que habla un lenguaje que no obedece a una posición demagógica sino a una convicción, es darle a entender que la demanda de servicios tiene que acentuarse; y hay que entender que es imposible satisfacer esos servicios frente a la infraestructura que algunos de ellos tienen, como es el caso de la medicina, y caso todavía superior porque incide también en los recursos humanos.

Pero, piensen ustedes, médicos del mañana, en un hecho baladí, aparentemente, pien- sen ustedes que hace algunos meses Santiago se estremeció porque hubo una protesta por la falta de carne. Y carne ha faltado siempre y faltará más. Si este fuera un pueblo revolucionario yo habría decretado veda, no por un mes sino por un año, pero no puedo hacerlo. Y comprendo la necesidad de hacerlo. Y ustedes que son médicos en ciernes piensen esto: el consumo per cápita, por habitante, de carne de vacuno en Chile, es de alrededor de 28 a 30 kilogramos año. En Estados Unidos es de 95 kilogramos, en Europa es de 85 a 87.

Chile importa todos los años 180 millones de dólares en carne, trigo, grasa, mantequilla y aceite. El año pasado importamos 80 millones de dólares en carne. Este año deberíamos importar 95 millones de dólares en carne. Importando 95 millones de dólares en carne, siempre existirá la realidad de que no alcanza la carne para todos y siempre el nivel de consumo per cápita estará en los porcentajes que señalaba.

$\mathrm{Si}$ nosotros pretendiéramos importar la carne necesaria para darle al hombre chileno lo que consume el hombre americano o europeo, tendríamos que importar 320 o 330 millones de dólares en carne. Si este país que tiene la segunda gran riqueza del mundo como propia, que es el cobre, este país que tiene un comercio exterior que le permite ingresos de 1.200 millones de dólares al año, este país tiene que gastar este año -y deberá gastarlos- cerca de 300 millones de dólares en alimentos. ¿Y por qué? Porque nosotros hemos creado, al hablarle a la gente de sus derechos y del drama de su realidad, y otros también han contribuido a ello, a darles la sensación de un derecho. Y qué derecho más esencial que el derecho a comer, a trabajar, a educarse, a defender la salud. Y qué responsabilidad más grande para los que somos médicos entender que en la economía de un país es esencial que se considere que el hombre necesita alimentarse, que necesita proteínas y que el rendimiento económico del país está precisamente relacionado con la capacidad que tiene para alimentar a sus niños.

$\mathrm{Y}$, sin embargo, nosotros tenemos que comprender que Chile no puede importar la cantidad de carne necesaria, pero al mismo 
tiempo se diría: Bueno, reemplacémosla por la carne de ave, por carne de cerdo, por carne de ovino. Pero, no hay posibilidad de hacerlo de inmediato, y la demanda es mayor que la oferta. Entonces hay que volver la vista al mar y pensar: ahí está la merluza, la pescada; y ahí está donde comienza también aquella situación que incide en la incomprensión y la ignorancia de los problemas esenciales, de los intereses que pesan sobre los países dependientes como el nuestro. Y nosotros lo hemos vivido.

¿Y por qué el silencio de los médicos? ¿Y por qué no la presencia, como organización, de los médicos? ¿Por qué no la proyección necesaria y fundamental de su acción, para decirle a un país como el nuestro -teniendo los conocimientos que deben tener- que no disponemos de las proteínas necesarias en la carne de vacuno, que no podemos dar la carne de cerdo o la carne de ave, que el proceso de formación de una producción avícola necesita por lo menos 4 o 5 años, en su desarrollo. Y para qué hablar de una masa ganadera, porque las vacas no se reproducen como los conejos, ¿verdad? Por lo tanto se necesita bastante más tiempo para tener una masa ganadera. Entonces, uno se pregunta por qué ese silencio y por qué se permite, por ejemplo, que se cree toda una atmósfera para desfigurar una iniciativa que tiende a posibilitar que la gente reciba las proteínas que no podemos darle de otra manera. Y cómo ser indiferente, desde el punto de vista médico, ante un proceso que no puede escapar a la responsabilidad del que sabe que ahí se puede entregar a la gente un alimento que tiene riqueza proteínica y que le permite a la gente comprar, en relación de uno a seis o siete que es el valor de la merluza, o en la carne.

Sin embargo, toda una batalla, todo un proceso, que va más allá, inclusive de los aspectos políticos internos y que aquí, en esta cátedra y con el derecho que me diera el profesor Roa yo puedo analizar. Toda una campaña, por ejemplo, destinada a hacer creer que la ayuda que ha significado el arriendo de los barcos soviéticos que ha permitido incrementar el consumo de pescado en niveles nunca vistos, triplicándolo y cuadruplicándolo, estaba destinado a espiar. ¿Qué cosa? Nuestras costas, nuestras bahías, nuestros mares, para la hipotética "guerra que vendrá".

Escándalo por cinco barcos soviéticos que han venido a entregarnos la pesca de alta mar, que somos incapaces de hacer, porque no tenemos los recursos necesarios. Pero, silencio cuando el señor Nixon bombardea Vietnam, país pequeño, que tiene como nosotros el derecho digno a ser un país que por su propio esfuerzo haga su propio destino. Pero, silencio cuando el señor Nixon en defensa de sus intereses va a conversar a la Unión Soviética o a la República Popular China. Pero, protestas porque un país pequeño como el nuestro, quiere romper la tradición que lo obliga y lo amarra a una dependencia económica para buscar en la independencia económica la posibilidad de cauces y desarrollo que necesitamos y que no hemos podido tener.

Y el médico, entonces, ¿puede estar ausente en estos hechos que no tienen una definición política? Y por eso decía que un profesor conservador, cargado de años y un médico conservador más joven, ambos maestros ilustres, en un momento de la vida conjugaron con un socialista, que sin ser maestro universitario, ha contribuido a hacer posibles las leyes más fundamentales en la medicina chilena y no ha habido fronteras a nuestra concepción de la responsabilidad de ser médico y la ética que nos obligaba a levantar nuestra voz para decir que un pueblo enfermo es un pueblo sin destino y lo que más vale es el capital humano, que todo es reemplazable menos la pareja humana, el hombre y la mujer.

Por eso, es que yo les digo a ustedes que para nosotros, es el proceso social el que va creando la dignidad y ello implica en la lucha de los pueblos el mayor acceso a la cultura, a la mayor conciencia de los derechos y ello implica, también, su mejor organización. Lo humano es sujeto y no es objeto. Los que profesamos algunas teorías o principios que emanan de hombres de pensamiento filosófico tan respetable como Engels, Marx o Lenin, sabemos lo que es la imaginación del hombre y que es precisamente una protesta nuestra concepción ideológica por la pérdida del valor de sí mismo y que sea el hombre transformado en una cosa. 
Es por eso que luchamos contra la deshumanización que implica que el automatismo que lleva, y conlleva, la concentración característica del régimen capitalista.

Vale decir, que nosotros concebimos la salud como un proceso dialéctico, biológico y social, producto de la interacción entre el individuo y el medio ambiente, influido por las relaciones de producción en una sociedad dada que se expresa en niveles de bienestar y deficiencia física y mental. Por lo tanto, como lo dijera con palabras distintas a lo largo de esta deshilvanada conversación, la salud es primero que nada un problema de estructura económica y social de niveles de vida y cultura.

Por eso, como lo dije también, el médico moderno debe tener una gran amplitud de criterio y al mismo tiempo modestia, para conocer las limitaciones de su acción.

La definición de una nueva ética médica orientada a servir al pueblo que se ajusta al proceso de liberación de las injusticias en que los chilenos estamos empeñados debe ser hecha colectivamente con la activa participación de los trabajadores de la salud a todos los niveles de la comunidad.

Ya no basta el médico solo y aislado, es el médico de equipo, es el médico de conjunto, son los trabajadores de la salud. Lo he dicho tantas veces con palabras simples, el más brillante cirujano nada puede hacer sin la auxiliar o la enfermera, e inclusive, sin la cuidadora, esa que está junto al enfermo, cuando el cirujano sigue operando o cuando dejó el hospital.

El no entender el aporte que implica el resto de los que trabajan y que los trabajadores de la salud, se unan todos, y el pretender establecer diferencias y consagrar distancias, porque uno pasó por la universidad y el otro no, es algo arcaico que además de ser injusto implica un menor rendimiento.

Además, indiscutiblemente, es fundamental y necesario abrir las posibilidades de expectativas a aquellos que trabajan en los servicios de salud, y puedan en función de facilidades avanzar en el conocimiento, en el estudio, en el progreso y algún día pudiera ser cierto que a Medicina llegaran algunos que entraron a trabajar en los servicios y que lograron por su propio empeño, con facilidades y una concepción distinta, graduarse después de haber aprendido lo que no recibieron en la universidad y que por último le entregó por su propia convicción su propia capacidad.

Por ello -repito- que es fundamental entender que en esta época y a esta realidad corresponde una apreciación distinta y diferente de los valores que tradicionalmente antes se manejaban o se tenían.

Quiero destacar que un aporte significativo de elaboración de esta nueva ética la he hecho yo a la comunidad universitaria, médica, de esta casa de estudios, al elaborar en la Reforma Universitaria una nueva promesa solemne del graduado.

Esa nueva promesa solemne del graduado es la que quiero leer para terminar mis palabras.

"Prometo que el propósito fundamental de mi labor profesional será servir al prójimo y a la comunidad en el campo de la Salud, con plena conciencia de mi responsabilidad social y ética. Contribuir con mi conocimiento y mis acciones a preservar la salud del hombre sano, a recuperar la salud del enfermo y a aliviar el dolor de los que sufren, a actuar siempre en beneficio de los enfermos y jamás posponer esta meta por intereses intelectuales o materiales. No hacer nunca daño de palabra ni al hombre sano o enfermo. No dar reglas ni utilizar procedimientos que aceleren la muerte ni dar consejos con este fin. No rehuir por ninguna razón el consejo de quienes estando mejor preparados que yo puedan contribuir al alivio de un enfermo, ni a actuar cuando otros puedan hacerlo mejor y estén dispuestos a ello. Prepararme científica y técnicamente en mi disciplina, antes de actuar y mantenerme siempre en estudio de ella, perfeccionando mis conocimientos y destrezas sin apartarme nunca de la honrada búsqueda de la verdad. Guardar el secreto de cuanto me haya sido confiado o conocido directa o indirectamente en razón del ejercicio de mi profesión, salvo aquellos casos en que los afectados me autoricen a dar a conocer dichos secretos o cuando el ministerio de la Ley lo ordene en beneficio de la sociedad. 
Enseñar con generosidad a quienes quieran formarse en el campo de la salud, de los médicos que lo deseen, en mi conocimiento.

Respetar en sus derechos, como persona y como funcionario, a todos los integrantes de mi grupo de trabajo, colaborar con el trabajo de los demás que lo requieren, en la medida de mis posibilidades, luchar por los cambios sociales que conduzcan a una sociedad libre de la injusticia, la enfermedad y la miseria, y abierta a todas las formas de expresión del espíritu.
Ahora, si cumplo esta promesa y no la quebranto, que los frutos de la vida y el arte sean míos, que sea siempre honrado por todos los hombres, y que lo contrario me ocurra, si la quebranto".

Yo tengo fe en ustedes, y sé que este juramento y el hipocrático darán el destino luminoso a una juventud médica, que tiene una nueva ética y un nuevo sentido de la responsabilidad.

(Aplausos) 